\title{
Gender Representations in English Text book: Critical Discourse Analysis
}

\author{
Fahimah Saifuddin
}

English Linguistics, Faculty of Cultural Sciences, Universitas Padjajaran Bandung

\begin{abstract}
This study was an attempt to examine different areas of gender in representation of women and men in English textbooks used by the lecture in teaching SFL (Systemic Functional Linguistics) in universitas Padjadjaran written by Eva Tuckita Sari Sujatna. This study uses quantitative and qualitative method by counting the frequence calculate the frequency of occurrence of nouns, names, pronouns, and adjectives that show women and men and analyzing the use of names, nouns, pronouns and adjectives attributed to women and men. The findings revealed that the manifestation of women and men in the English textbooks was not fair. The presence of men was more highlighted than that of women in terms of names, nouns, pronouns and adjectives.
\end{abstract}

Keywords - Critical Discourse Analysis, SFL, English Text book.

\section{INTRODUCTION}

In many formal and non-formal education, the teachers and the students need a textbook as a barometer in teaching and learning. According to Bahman and Rahimi (2010) textbooks play a very important role in the education of EFL because generally through textbooks that students get acquainted with the culture of the target language and values. They also added that based on different cultures, different characteristics and behaviors are expected from both genders.

This study is a study of gender applied in a textbook. According to Sasongko (2009) gender is the different roles, functions, and responsibilities between men and women are socially constructed and can change according to the changing the times. She differ the geder and sex. She argue that Sex is the differences of sex biologically. Physically attached sex as a means of reproduction.

In the textbook, espesially linguistic textbook such as syntaxs, pragmatics, and morphologies, most author more often use the example of a sentence in order to give a better understanding to his students. The example can not be separated from the use of the subject by the author using the name of someone both women and men, nouns, pronouns. In a sentence also can not be separated from the use of adjectives to explain the subject or object.
From the statements above, the researcher wants to know inequality of gender shown in the English textbooks used by the lecture in teaching SFL (Systemic Functional Linguistics) in universitas Padjadjaran written by Eva uckita Sari Sujatna.

The data of this study are taken from the English textbook written by Eva uckita Sari Sujatna. The title of the book is 'understanding Systematic Functional Linguistics' that published by Unpad press on January 2013. The textbook use english language.

\section{AIM OF THE STUDY}

The aims of this study is to analyze gender representation in English textbooks used by the lecture in teaching SFL (Systematic Functional Linguistics) in universitas Padjadjaran written by Eva uckita Sari Sujatna. For this purpose, these textbooks were analyzed in terms of names, nouns, pronouns and adjectives allocated to each sex.

\section{METHOD}

This study analyzes the textbook. According to Hamad (2005) discourse analysis is a tool to capture the meaning of a discourse. He also said that the use of method of discourse analysis is to analyze the distinctive aspects of the outside and the inside of a manuscript to find concepts and giving the meaning then compare the aspects of explicit and implisist and be analyzed, finally draw the conclusion (Hamad, 2005).

This study employs both qualitative and quantitative approaches in which frequency counts of female and male referring terms, frequency of first-place occurrences of words attributed to women and men were examined. In order to find out whether women and men were treated equally in the English textbooks used by the lecture in teaching SFL (Systematic Functional Linguistics) in universitas Padjadjaran written by Eva uckita Sari Sujatna, all parts of the textbooks were investigated including the examples as well.

\section{FINDINGS AND DISCUSSIONS}

Lakoff (1975) have been attention to linguistic differences between genders, numerous empirical studies have been conducted examining linguistic features related 
specifically to men and women. some researchers claim that the gender of a speaker or writer affect the use of language is very small, and that other factors such as social status or age of the speaker and / or listeners may have a greater effect on the use of language (Brouwer, Berryman-Fink \& Wilcox, Ishikawa in Ishikawa 2014).
The analysis regarding whether nouns, names, pronouns and adjectives attributed to females and males have equal frequencies in the English textbooks used by the lecture in teaching SFL (Systemic Functional Linguistics) in universitas Padjadjaran revealed the following results as shown below:

Table.1: Frequency of Names, Nouns, Pronouns and Adjectives Attributed to Females and Males in the English textbooks used by the lecture in teaching SFL (Systemic Functional Linguistics) in universitas Padjadjaran written by Eva uckita Sari Sujatna.

\begin{tabular}{|l|l|c|c|c|c|c|}
\hline \multicolumn{1}{|c|}{ Textbook } & Sex & Names & Nouns & Pronouns & Adjectives & Presence (P) \\
\hline $\begin{array}{l}\text { English Textbook: } \\
\begin{array}{l}\text { Understandding Systemic } \\
\text { Functional Linguistics written } \\
\text { by Eva uckita Sari Sujatna }\end{array}\end{array}$ & $\mathrm{M}$ & $20(86.95 \%)$ & $10(76.92 \%)$ & $21(65.62 \%)$ & $1(16.66 \%)$ & $52(70.27 \%)$ \\
\cline { 2 - 7 } & $\mathrm{F}$ & $3(13.04 \%)$ & $3(23.07 \%)$ & $11(34.37)$ & $5(83.33 \%)$ & $22(29.73 \%)$ \\
\hline \multicolumn{1}{|c|}{ Total } & & $\mathbf{2 3}$ & $\mathbf{1 3}$ & $\mathbf{3 2}$ & $\mathbf{6}$ & $\mathbf{7 4}$ \\
\hline
\end{tabular}

Explanation:

The numbers in square brackets represent the percentages, and the ones in parentheses the instances

$\mathrm{M}=$ Male

$\mathrm{F}=$ Female

As shown in table 1 that the percentage of all the names, nouns, pronouns and adjectives of men is $79 \%$. In order the author uses $20(86.95 \%)$ name of male such in examples bellow:
(1) Jack read the text loudly
(2) James opened the bottle
(3) Ryan bought a book yesterday
(4) Tom is the teacher
(5) Michael Jackson was the legend (p. 43)

It can be seen from the data mantioned on this textbook that most of the examples on it include in the name of people who are male one. of the number of names used by the author of the textbook is more likely to use the names of men than women. It can be seen from a few of the examples above that the researcher mentions as the representative example that the names used are the male name such as Jack, James, Ryan, Tom, and Michael Jackson and the other that the researchers do not mention all.

The author used the pronoun consisting of 21 (65.62\%) male pronoun such in examples bellow:
(6) He saw a green book on the table
(p. 24)
(7) He wasn't by me
(p. 40)
(8) They blamed him

The data shown that the use of male pronouns are more dominant in this textbooks, as described above, more than half, the authors used the examples of using the subject or object in the form of pronouns that shows male such as he and him as the examples in the data (6), (7), and (8).
The use of nouns that mantion in the example of the textbook are $10(76.92 \%)$ times the author used male showing the male such in the data bellow:
(9) My father made my brother a kite
(10) He is not a smart boy
(p. 6)

The tendency to use the word my father and my brother, as seen in the example above, were repeated up to 10 times compared with the use of a noun that showed women like the word my mother or my sister in this textbook shows that the authors prefer to use the noun men.

In addition to use of name, pronoun, noun, researchers also examined the use of adjectives frequently used by the author in his textbook. But in terms of adjectives, author more inclined to use words that indicate the characteristics of women as seen in the example below:

(11) Not so very much more beautifully(p. 71)

(12) What a beautiful eyes you have (p. 55)

The data above shows that the author often uses the word beautiful in the example mention in her teksbook, this words indicate the characteristic of the woman. author uses the word beautiful twice in his textbooks. The data shows that the author wanted to highlight the characteristics of women than men.

\section{CONCLUSION}

This study was an attempt to investigate and analyze gender representation of English textbooks used by the lecture in teaching SFL (Systemic Functional Linguistics) in universitas Padjadjaran written by Eva uckita Sari Sujatna. The results revealed that there is not a fair between females and males in this textbook that there is a big gender gap between the portrayal of females and males in the textbook after investigated. Sexism is shown in many different areas in this textbook such as the use of names, nouns, pronouns, and adjectives in many examples 
mantioned in this textbook. So it can be concluded that in the textbook investigated, women were almost discriminated and invisible in terms of names, nouns, pronouns.

\section{REFERENCES}

[1] Hamad, I. (2005). Lebih Dekat dengan Analisis Wacana. Mediator Vol.8 No. 2 , 328.

[2] Ishikawa, Y. (2014). Gender Differences in Vocabulary Use in Essay Writing by University Students. Elsevier.

[3] Masoumeh Bahman, A. R. (2010). Gender representation in EFL materials: an analysis of English textbooks of Iranian high schools. Elsevier.

[4] Sasongko, S. S. (2007). Konsep dan Teori Gender. ISBN, 7 .

Textbook:

[5] Sujatna, E. T. (2013). Understanding Systematic Functional Linguistics. Bandung: Unpad Press. 